\title{
Age-Related Changes in Humoral and Cell- Mediated Immunity in Down Syndrome Children Living at Home
}

\author{
GILLIAN LOCKITCH, V. K. SINGH,' M. L. PUTERMAN, W. J. GODOLPHIN, S. SHEPS, \\ A. J. TINGLE, F. WONG, AND G. QUIGLEY \\ Departments of Pathology, Pediatrics and Health Care and Epidemiology of the University of British Columbia, \\ and British Columbia Children's Hospital, Vancouver, British Columbia, Canada
}

\begin{abstract}
Abnormalities of humoral and cell-mediated immunity have been described in Down syndrome but reported findings have been inconsistent. Confounding factors have included age, institutional versus home life, hepatitis $B$ antigenemia, and zinc deficiency. To clarify this problem, we studied 64 children with Down syndrome (DS) compared with an age-matched control group. All children had always lived at home. All the DS children were negative for hepatitis B surface antigen. Serum zinc concentration in the DS group was on average $12 \mu \mathrm{g} / \mathrm{dl}$ lower than age-matched control children. They also had significantly lower levels of immunoglobulin $M$, total lymphocyte count, $T$ and $B$ lymphocytes, and $T$ helper and suppressor cells. In vitro lymphocyte response to phytohemagglutinin and concanavalin A was significantly reduced at all ages in the DS group. Lymphocyte response to pokeweed mitogen increased with age in control children but decreased in the DS children. By $18 \mathrm{yr}$, the mean response for DS was $60000 \mathrm{cpm}$ lower than controls. The DS group had significantly higher concentrations of immunoglobulins $A$ and $G$ than controls and the difference increased with age. Complement fractions $\mathrm{C} 3$ and $\mathrm{C} 4$ were also higher in the DS group at all ages. The number of $\mathrm{HNK}-1$ positive cells was higher in the DS group than controls at all ages. When hepatitis and institutionalization are excluded as confounding factors, DS children still differ in both humoral and cell-mediated immunity from an age-matched control group. (Pediatr Res 22: 536-540, 1987)
\end{abstract}

\section{Abbreviations}

DS, Down syndrome

MSLT, mitogen-stimulated lymphocyte transformation

HBSAg, hepatitis B surface antigen

PHA, phytohemagglutinin

DNCB, dinitrochlorobenzene

AA, atomic absorption

ELISA, enzyme-linked immunosorbent assay

NK, natural killer

smIg, surface membrane immunoglobulin

FITC, fluorescein

PWA, pokeweed mitogen

ConA, concanavalin A

TLC, total lymphocyte

Received January 13, 1987; accepted June 24, 1987

Correspondence and reprint requests to Dr. G. Lockitch, Department of Pathology, British Columbia Children's Hospital, 4480 Oak Street, Vancouver, British Columbia, Canada V6H 3 V4.

Supported by the British Columbia Health Care Research Foundation

' Present address, Department of Microbiology and Immunology, Medical University of South Carolina, 171 Ashley Avenue, Charleston, SC 29425.
TC, T cells

HC, helper cells

SC, suppressor cells

Repeated and chronic respiratory infections are an important cause of morbidity in children with DS (Trisomy 21) $(1,2)$. DS children are at increased risk for leukemia $(3,4)$ and have a greater incidence of autoimmune disorders than the general population (5). This suggests that immunodeficiency may be an important component of DS (6). Abnormalities of cell-mediated, humoral, and phagocytic functions have been described in DS $(6-19)$ but the findings have not been consistent. This inconsistency has been variously attributed to factors such as age variability between subjects and controls, institutionalization as a cause of exposure to frequent infections, and persistence of $\mathrm{HBsAg}$ in the blood of DS subjects $(6,15,19,20)$.

Zinc deficiency is known to depress immune responses in both inherited and acquired deficiency states $(21,22)$. Low serum zinc concentration has been reported in DS (23-25) although again findings have not been consistent (26). A moderate reduction in serum zinc concentration was shown to decrease the zinc-dependent activation of thymulin, a circulating thymic hormone $(25,27)$, and thus affect acquisition of immunocompetence by T lymphocytes (27). Thymulin was shown to be low in children with DS (25). In a single study it was reported that 2 months of daily oral zinc sulfate therapy in 12 DS children improved the in vitro response of lymphocytes to high dose PHA, neutrophil chemotaxis, and skin reactivity to DNCB as well as increasing serum zinc levels (23). This supported a possible role for zinc deficiency in the immunodeficiency of DS. Differences in zinc status may also therefore have contributed to the inconsistency of reported data in DS.

To resolve these controversies, DS children who had always lived at home were studied together with age- matched controls to determine differences in zinc status, cell-mediated, and humoral immunity.

The objectives of the study were to determine whether noninstitutionalised DS children differ from healthy like-age normal control children in humoral and cell-mediated immunity. If differences were demonstrated, were they related to serum zinc status or persistent hepatitis antigenemia? Did DS children with chronic respiratory problems, nasal discharge and cough differ from DS children without these chronic symptoms?

\section{SUBJECTS}

The DS study group consisted of 64 DS children, aged 1-19 536

$\mathrm{r}$, living in a home environment, who attended our research 
clinic for the first time during a 6-month period in 1984/85. Recruitment occurred through a series of meetings at which the study was described to parents. The sole selection criteria were appropriate age and willingness of families to participate in the study. Three DS children had surgically corrected cardiac defects and three others were on treatment for hypothyroidism. None was acutely ill at the baseline visit although more than one-third reported chronic symptoms such as nasal congestion and cough. The latter are called the "symptomatic" group.

Data were obtained over the same period from 88 control children. A randomly selected subset of 30 children provided control data for the immunology tests. All controls were normal healthy children aged from 1-19 yr drawn from an unselected community population living in the same areas as the DS group who had no clinical signs of illness when blood samples were taken. Informed consent was given by the parents of all subjects. The study protocol was approved by the University of British Columbia Clinical Screening Committee for Research involving Human Subjects.

\section{METHODS}

A brief clinical history was obtained and a single venous blood sample collected aseptically into a heparinized vacutainer for immunology and protein studies, and into a tracemetal free collection tube (Becton Dickinson) for the trace metal studies. Zinc was measured by flame AA spectrometry using a Varian AA 1475 . Serum copper was also measured by electrothermal AA on the Varian GTA-95 since oral zinc therapy may impair copper absorption and lower serum copper concentration. Proteins were measured by nephelometry (Behring LN Nephelometer). A blood sample from each DS child was screened by ELISA for HBsAg and anti-HBsAg.

Lymphocytes were separated by standard techniques (28) using density gradient centrifugation in Ficoll-Paque (Pharmacia). Lymphocyte cell surface marker analysis was performed by 2 color direct immunofluorescence. For determination of $T$ cell populations we used monoclonal antibodies from Becton Dickinson Monoclonal Center (Leu- 1 for $T$ cells, Leu-2a for Tsuppressors, Leu-3a for T-helpers and Leu-7 (HNK-1) for NK cells. B lymphocyte was assayed with FITC-goat-antihuman IgG $+\operatorname{IgA}+\operatorname{IgM}(\mathrm{H}+\mathrm{L})$ antibodies (Zymed Laboratories). A blank of mouse antibody was run in parallel and its value subtracted from the test results. Lymphocyte blastogenic response to mitogens, PHA, PWM, and ConA were determined using microtitre plate culture technique and with optimal concentration of mitogen, in triplicate, as previously described (29).

Statistical analysis. Clinical group differences and age effects on chemistry and immunology variables were investigated using analysis of variance where age was treated as a linear effect. The effect of zinc and copper on the other variables was also studied by analysis of covariance. All calculations were performed using SAS Statistical Software (30). Since a large number of variables was studied, Bonferroni corrections were taken into account when determining significance of a result.

\section{RESULTS}

All 64 DS children were negative on screening for HBsAg and for anti-HBsAg. This excluded persistent hepatitis antigenemia from further consideration as a confounding factor in this study.

The mean age of the 23 "symptomatic" DS children was lower $(6.5 \mathrm{yr})$ than that of the 41 "asymptomatic" children $(10 \mathrm{yr})$ $(p<0.006)$.

Zinc and copper. The effect of age on zinc and copper levels was similar in both the DS and control groups (zinc $p=0.32$, copper $p=0.33$ ) (Figs. 1 and 2). In both groups zinc levels decreased with age but the change was not significant $(p=0.08)$, while copper levels decreased significantly with age $(p<0.0001)$. Zinc levels were on average $11.78 \mu \mathrm{g} / \mathrm{dl}$ lower in the DS group $(p<0.001)$ while copper was on average $7.97 \mu \mathrm{g} / \mathrm{dl}$ higher $(p=$ $0.03)$.

Immunoglobulins. Figures 3-5 show the effect of age and diagnostic group on immunoglobulin $\mathrm{G}, \mathrm{M}$, and A. For IgM the effect of age was the same in both groups $(p=0.16)$ while it differed significantly with respect to $\operatorname{IgA}(p=0.001)$ and $\operatorname{IgG}$ $(p=0.004)$. IgM levels were on average $55 \mathrm{mg} / \mathrm{dl}$ lower in the DS group $(p<0.0001)$ and increased significantly with age in both groups $(p=0.001)$. IgA and IgG increased with age in both groups, with a more rapid increase in the DS group. IgA and IgG levels were higher in the DS group at all ages.

After adjusting for age and group effects, IgA levels were correlated negatively with serum zinc $(p=0.02)$ and positively with serum copper $(p=0.01)$ while IgM and IgG were correlated with neither.

Complement fractions. The effect of age on the logarithm of complement fractions $\mathrm{C} 3 \mathrm{c}$ and $\mathrm{C} 4$ was the same in both groups. The average level of $C 3 c$ increased with age $(p=0.02)$, serum zinc $(p=0.006)$, and serum copper $(p<0.0001)$ and was also significantly higher in the DS group $(p<0.0001)$. Mean (SD) C 3 c concentration was $82(15) \mathrm{mg} / \mathrm{dl}$ in the DS children and 69 (11) $\mathrm{mg} / \mathrm{dl}$ in controls. The average level of $\mathrm{C} 4$ depended on neither age $(p=0.11)$ nor serum zinc $(p=0.52)$ but was correlated with serum copper $(p<0.0001)$ and higher in the DS group ( $p<0.0001)$. Mean (SD) C4 concentration was 31 (13) $\mathrm{mg} / \mathrm{dl}$ in the DS children and $18(5) \mathrm{mg} / \mathrm{dl}$ in controls. No difference was found between the "symptomatic" and "asymptomatic" DS children for mean concentrations of serum zinc

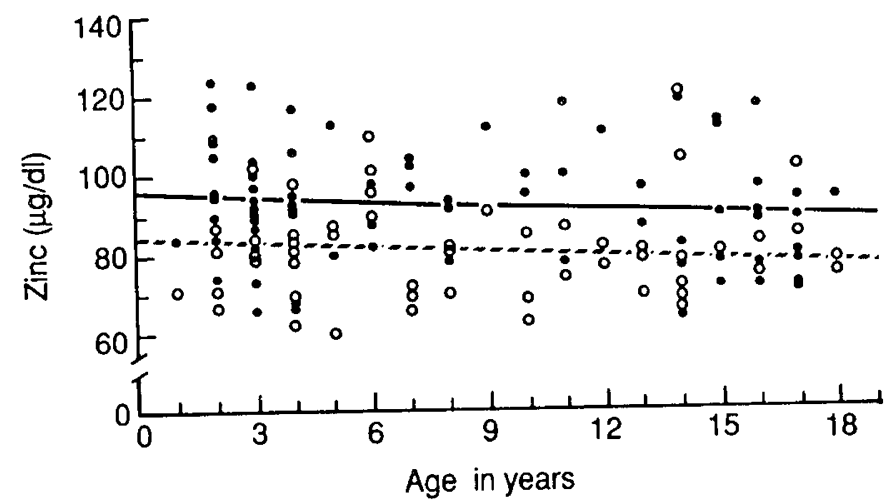

Fig. 1. Serum zinc concentration by age for DS children $\left(\mathrm{O}_{---}\right)$and controls $(-)$. For DS, zinc $=84-0.37$ age, for controls zinc $=96$ -0.37 age, $R^{2}=0.18$.

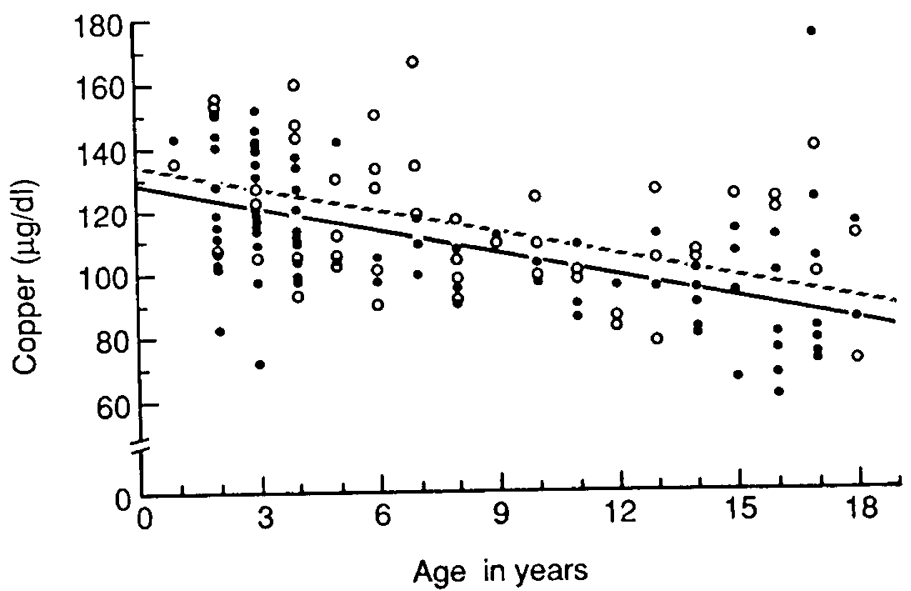

Fig. 2. Serum copper concentration by age for DS children $\left(\mathrm{O}_{---}\right)$ and controls $(-)$. For DS, copper $=133-2.34$ age, for controls copper $=127-2.34$ age, $R^{2}=0.36$. 


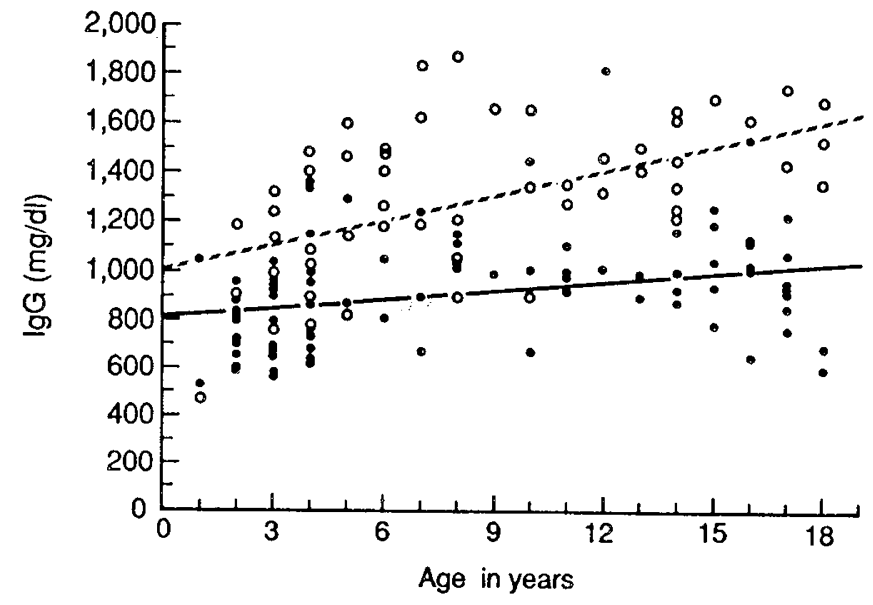

Fig. 3. Serum IgG concentration by age for DS children $\left(\mathrm{O}_{---}\right)$and controls $(-)$. For DS, $\mathrm{IgG}=997+34.17$ age, for controls $\mathrm{IgG}=$ $813+11.76$ age, $R^{2}=0.47$.

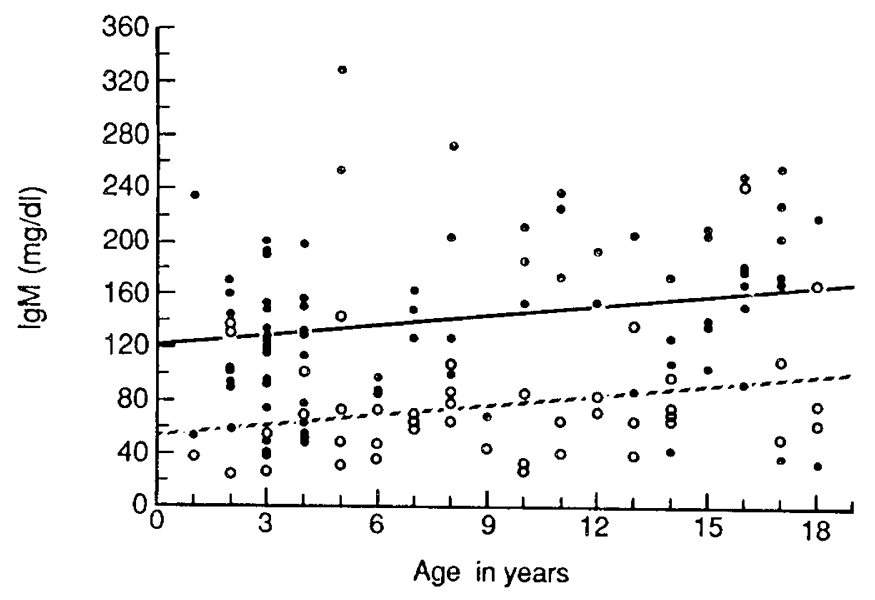

Fig. 4. Serum IgM concentration by age for DS children $\left(\mathrm{O}_{---}\right)$and controls - - . For DS, IgM $=54+2.51$ age, for controls $\operatorname{IgM}=122$ +2.51 age, $\mathrm{R}^{2}=0.34$.

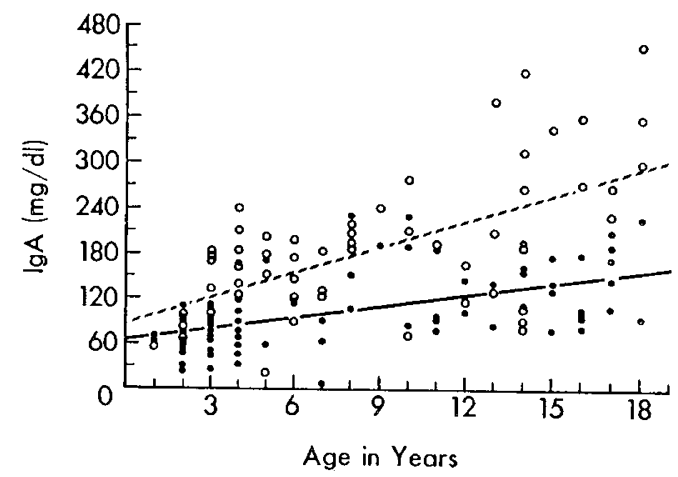

Fig. 5. Serum IgA concentration by age for DS children $\left(\mathrm{O}_{---}\right)$and controls $(\longrightarrow)$. For DS, $\operatorname{IgA}=86+11.57$ age, for controls $\operatorname{IgA}=63$ +5.21 age, $R^{2}=0.51$.

$(p=0.72)$, copper $(p=0.31), \operatorname{IgG}(p=0.83), \operatorname{IgA}(p=0.11)$, $\operatorname{IgM}(p=0.41)$, or $\mathrm{C} 4(p=0.13)$. C3c was slightly higher in the symptomatic DS group [87 (4)] $\mathrm{mg} / \mathrm{dl}$ than in the asymptomatic group $[79(15)] \mathrm{mg} / \mathrm{dl}(p=0.04)$.

Lymphocyte subsets. Figures 6-8 show the effect of age and diagnostic group on the TLC and helper and suppressor TC counts. For TLC, TC, T HC, and T SC, the effect of age was

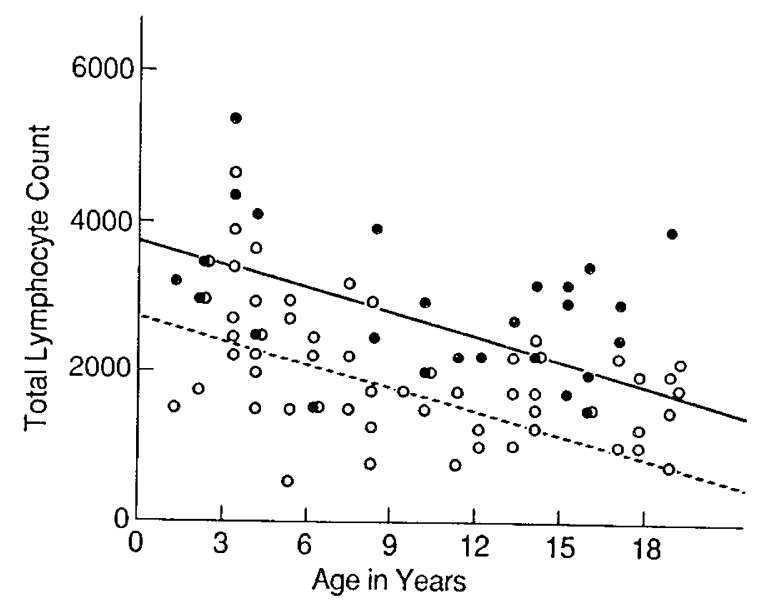

Fig. 6. Total lymphocyte count by age for DS children $\left(\mathrm{O}_{---}\right)$and controls $(-)$. For DS, TLC $=2735-80.17$ age, for controls TLC $=3745-80.17$ age, $\mathrm{R}^{2}=0.35$.

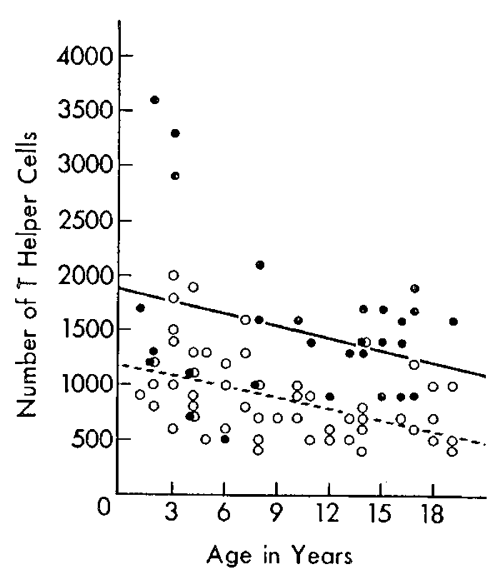

Fig. 7. T HC count by age for DS children $\left(\mathrm{O}_{---}\right)$and controls $(-)$. For DS, HC $=1215-36.12$ age, for controls $\mathrm{HC}=1890-$ 36.13 age, $\mathrm{R}^{2}=0.35$.

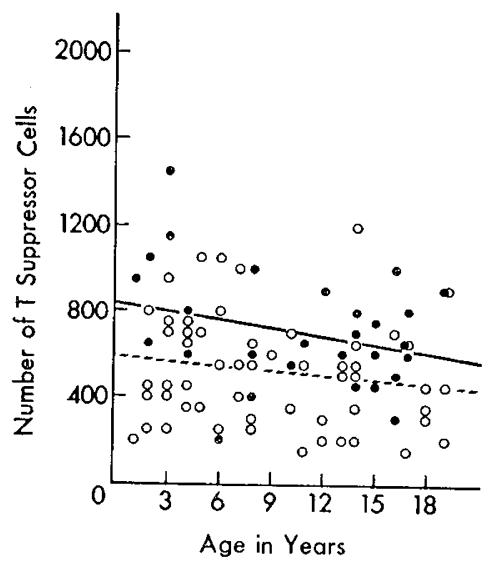

Fig. 8. T SC count by age for DS children $\left(\mathrm{O}_{---}\right)$and controls $(-)$. For DS, $\mathrm{SC}=630-12.88$ age, for controls $\mathrm{SC}=837-12.88$ age, $R^{2}=0.16$.

similar in the DS and control groups $(p>0.42)$ in all cases. TLC, TC, and HC numbers declined significantly with age $(p<$ 0.001 in all cases) while the relationship was weaker for SC ( $p=$ $0.04)$. Counts in the DS group were significantly lower than in the controls for TLC, TC, HC, $(p<0.0001)$ and for SC $(p=$ 
0.0003). The effect of age on B cell count (Fig. 9) differed between the two groups $(p=0.03)$. In the control group B cells declined significantly with age $(p=0.01)$ while in the DS group mean levels were not different across ages $(p=0.08)$. After adjusting for age and group effects, there was no correlation of lymphocyte subset counts with zinc or copper concentration.

DS children had significantly higher numbers of cells positive for the Leu-7 (HNK-1) marker, which reacts with the population of large granular lymphocytes including NK cells $(p=0.009)$. The mean number of HNK-1 cells was $290 / \mathrm{mm}^{3}$ in DS children and $165 / \mathrm{mm}^{3}$ in controls.

MSLT. Figures 10 and 11 show the effect of age and diagnostic group on MSLT for PHA and PWM. The effect of age was the same in both groups for PHA and ConA but significantly different for PWM $(p<0.0001)$. A slight but not significant increase of MSLT with age was seen in both groups for PHA and Con A. The average response was $35,000 \mathrm{cpm}$ higher in the controls for PHA $(p=0.001)$ and $54,000 \mathrm{cpm}$ higher in the controls for Con A $(p<0.0001)$. For PWM, the average MSLT increased with age in the controls and decreased in the DS group; the average $\mathrm{cpm}$ were approximately equal in the two groups at $6 \mathrm{yr}$. By 18 yr the DS response was on average $60,000 \mathrm{cpm}$ lower. After adjusting for age and group effects, serum copper had no effect on MSLT $(p=0.29)$ while there was a weak inverse correlation

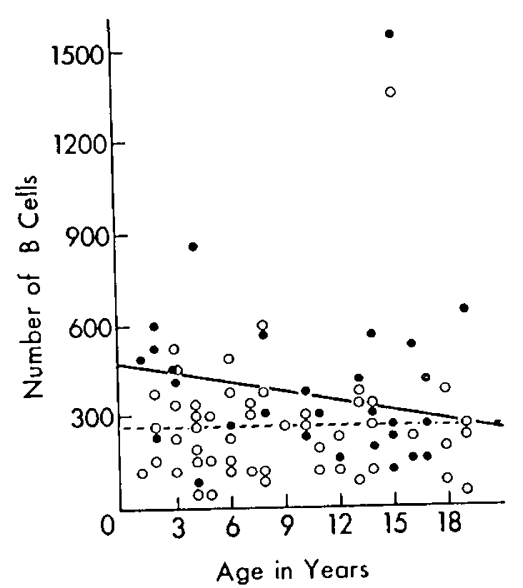

Fig. 9. B lymphocyte count (BC) by age for DS children $\left(\mathrm{O}_{---}\right)$and controls $(-$ For DS, $\mathrm{BC}=235+2.98$ age, for controls $\mathrm{BC}=496$ -14.38 age, $R^{2}=0.14$

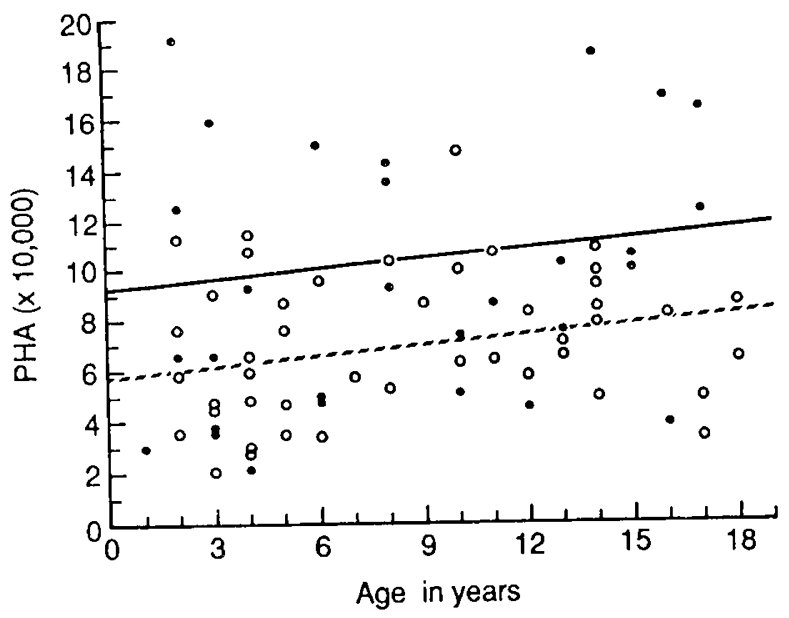

Fig. 10. In vitro lymphocyte transformation response to PHA by age for DS children $\left(\mathrm{O}_{---}\right)$and controls $(-)$. For DS, PHA $=5.76+$ 0.14 age, for controls $\mathrm{PHA}=9.26+0.14$ age, $\mathrm{R}^{2}=0.21$.

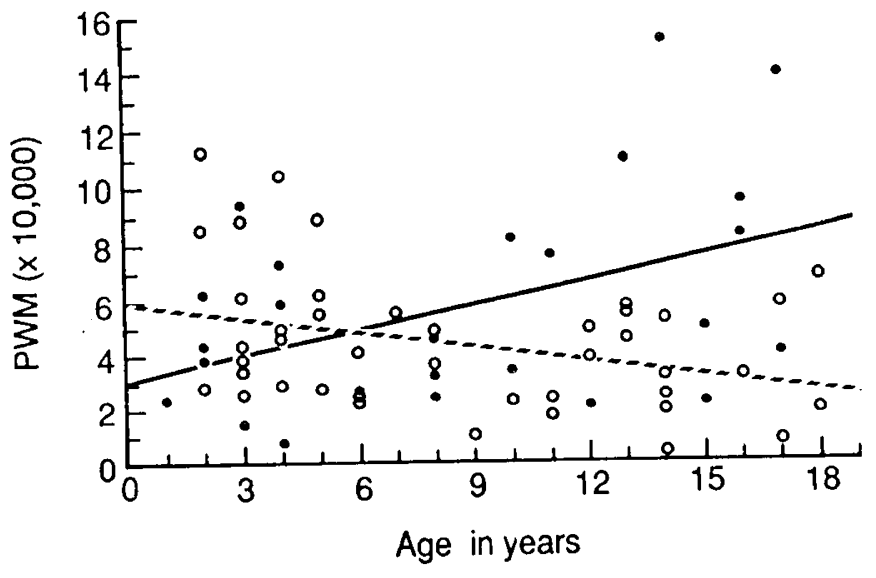

Fig. 11. In vitro lymphocyte transformation response to PWM by age for DS children (O-- ) and controls $(-)$. For DS, PWM $=5.89+$ 0.18 age, for controls $\mathrm{PWM}=3.04+0.31$ age, $\mathrm{R}^{2}=0.20$.

of serum zinc with MSLT ( $p=0.04$ for PWM, $p=0.06$ for PHA, and $p=0.14$ for Con A).

No difference was found between the "asymptomatic" and "symptomatic" DS groups for lymphocyte quantitation or response to mitogens with one exception. The asymptomatic group had a much higher percentage of HNK-1 positive cells $(18.5 \%)$ than the symptomatic $(9.6 \%)(p=0.004)$.

\section{DISCUSSION}

The major differences between DS and controls found herein were the markedly decreased TLC, T HC, and SC, PHA- and Con A-stimulated lymphocyte transformations, serum zinc and serum IgM levels, and the increased $\mathrm{HNK}-1$ positive cells and serum IgG and IgA.

Whereas the ability of lymphocytes to respond to PWM stimulation increases with age in control children, DS children show a significant decrease in response to PWM. We have shown that distinct differences exist between DS and control children that cannot be attributed to persistence of $\mathrm{HBsAg}$ or to institutionalization.

More than two-thirds of the DS children in comparison to age-matched controls were moderately zinc deficient as defined by a serum zinc level more than $10 \%$ below the mean of the control group. No significant correlation was found for serum zinc with lymphocyte subset counts or MSLT.

Plasma or serum zinc has been reported to be significantly lower in DS children (23-25), while studies comparing adult groups or a wide age range of subjects found similar zinc or copper concentrations in DS and non-DS subjects (26). The reduction of mean serum zinc to about $88 \%$ of the level in agematched controls suggests that a chronic state of moderate zinc deficiency may be present in our DS children. The reason for the low serum zinc in DS is as yet unexplained. Possible causes include inadequate dietary intake of zinc, abnormal absorption, redistribution in response to stress or infection, or increased needs. Dietary zinc intake was not specifically assessed in this study but based on parental contact, we have no reason to believe that dietary inadequacy is the explanation for the low zinc in the DS children. Mean serum zinc was no different in the "symptomatic" $(81 \mu \mathrm{g} / \mathrm{dl})$ and "asymptomatic" $(82 \mu \mathrm{g} / \mathrm{dl})$ DS groups so that the stress of chronic infection was not a factor in the low serum levels in this study.

Fabris et al. (25) suggested that a 20-30\% reduction in normal serum zinc level could increase the ratio of inactive to active circulating thymic hormone, thymulin, and thus affect acquisition of immunocompetence by $T$ cells. Although all lymphocyte subsets were lower in our DS children, the difference was most 
marked for the T cell subset, particularly HC. However, thymulin was not measured in our study.

Studies of cell-mediated immunity in DS have shown varied results with respect to numerical and functional variation from normal. Reasons may include failure to adjust for age effect or use of assays reacting to different cell surface markers to determine similar cellular subsets.

Other groups using surface markers have reported similar increases in HNK-1 cells in DS (16). Others (18) studying NK function rather than surface markers have shown no significant difference between DS and control groups for NK cytotoxicity and antibody-dependent cellular cytotoxicity in unseparated lymphocytes although the DS lymphocytes did show somewhat stronger activity. The Leu-7 marker is not exclusive for the NK cell population. This may partially explain the apparent inconsistency.

Reports of immunoglobulin and protein status in DS have also varied. Generally, hypergammaglobulinemia has been thought to reflect persistent or recurrent antigenic stimulation. A high prevalence of $\mathrm{HBsAg}$ positivity in several studies of DS appeared to provide a candidate antigen $(5,19,20)$. The importance of institutionalization for this problem has been controversial. HBsAg positivity in DS was reported as $28 \%$ in a large institution versus $3 \%$ in non-DS subjects in the same institution compared with $1.5 \%$ in DS subjects in a small institution (19). A study comparing DS and non-DS subjects matched for age and residence (home or institution) found that the presence of antithyroglobulin antibodies was positively correlated with the presence of $\mathrm{HBsAg}$ (5). In our study, no child was positive for $\mathrm{HBsAg}$ including nine children with raised titers of thyroid microsomal antibody. Etiologies other than persistent $\mathrm{HBsAg}$ must be sought to explain the marked variation in immunoglobulin profile in our DS group compared to controls.

Despite failure to show correlation of current serum zinc levels with the severely depressed total lymphocyte, TC and T HC counts and the depressed MSLT, the possibility that these problems were due to a chronic state of moderate zinc deficiency in the DS children in our study could not be excluded. A prospective study of zinc supplements, serial zinc levels and lymphocyte subset distribution, MSLT, and infections in DS children is in process to resolve this issue.

Acknowledgments. The authors acknowledge the help of Mary Godolphin, the Vancouver-Richmond Association for Mentally Handicapped People, and British Columbians for Mentally Handicapped People.

\section{REFERENCES}

1. Palmer S 1978 Influence of Vitamin A nutriture on the immune response: findings in children with Down's syndrome. Int J Vit Nutr Res 38:188-216

2. Oster J, Mikkelsen M 1975 Mortality and lifetables in Down syndrome. Acta Paediatr Scand 64:322-326

3. Miller RW 1971 Neoplasia and Down syndrome. Ann NY Acad Sci 171:637644

4. Robison LL, Nesbit ME, Sather HN, Level C, Shahidi N, Kennedy A, Hammond D 1984 Downs syndrome and acute leukemia in children: a 10-year retrospective study from Children's Cancer Study group. J Pediatr 105:235242
5. Ugazio AG, Jayakar SD, Marcioni AF, Duse M, Monafo V, Pasquali F, Burgio GR 1977 Immunodeficiency in Down's syndrome: relationship between presence of human thyroglobulin antibodies and HBsAg Carrier status. Eur J Pediatr 126:139-146

6. Burgio GR, Ugazio A, Nespoli L, Maccario R 1983 Down syndrome: a model of immunodeficiency. Birth Defects 19:325-327

7. Levin S, Nir E, Mogilner BM 1975 T System immune-deficiency in Down's Syndrome. Pediatrics 56:123-126

8. Burgio GR, Ugazio AG, Nespoli L, Marcioni AF, Botelli AM, Pasquali F 1975 Derangements of immunoglobulin levels, phytohemagglutin responsiveness and $\mathrm{T}$ and $\mathrm{B}$ cell markers in Down's syndrome at different ages. Eur $\mathbf{J}$ Immunol 5:600-603

9. Seger R, Buchinger G, Stroder J 1977 On the influence of Age on immunity in Down's syndrome. Eur J Pediatr 124:77-87

10. Franceschi C, Licastro F, Paolucci P, Masi M, Cavicchi S, Zanotti M 1978 T and B Lymphocyte subpopulations in Down syndrome. A study on noninstitutionalised subjects. J Ment Defic Res 22:179-191

11. Whittingham S, Pitt DB, Sharma DLB, MacKay IR 1977 Stress deficiency of the T-lymphocyte system exemplified by Down's syndrome. Lancet 1:163166

12. Spina CA, Smith D, Korn E, Fahey JL, Grossman HJ 1981 Altered cellular immune functions in patients with Down's Syndrome. Am J Dis Child $135: 251-255$

13. Barroeta O, Nungaray M, Lopez-Osuna S, Armendares F, Salamanca F, Kretschmer RR 1983 Defective monocyte chemotaxis in children with Down's syndrome. Pediatr Res 17:292-295

14. Burgio GR, Lanzavecchia A, Maccario R, Vitiello A, Plebani A, Ugazio AG 1978 Immunodeficiency in Down's syndrome: T-lymphocyte subset imbalance in trisomic children. Clin Exp Immunol 33:298-301

15. Ablin RJ 1978 Immunity in Down's syndrome. Eur J Pediatr 127:149-152

16. Maccario R, Ugazio AG, Nespoli L, Alberini C, Montagna D, Porta F, Bonetti F, Burgio GR 1984 Lymphocyte subpopulations in Down's syndrome: high percentage of circulating HNK-1+, Leu $2 \mathrm{a}^{+}$cells. Clin Exp Immunol 57:220percent
226

17. Bertotto A, Gerli R, Fabietti G, Arcangeli CDF, Bianchi S, Vaccaro R 1984 Immunodeficiency in Down's syndrome: analysis by OKT monoclonal antibodies. Thymus 6:365-367

18. Nurmi T, Huttunen K, Lassila O, Henttonen M, Sakkinen A, Linna SL, Tiilikainen A 1982 Natural killer function in trisomy-21 (Down's syndrome). Clin Exp Immunol 47:735-741

19. Sutnick AI, London T, Gerstley BJ, Cronlund MM, Blumberg B 1968 Anicteric Hepatitis associated with Australia antigen. JAMA 205:670-674

20. Hollingsworth DR, Hollingsworth JW, Roeckel I, McKean HE, Holland N 1974 Immunologic reactions and Australia antigenemia in Down syndrome. J Chronic Dis 27:483-490

21. Moynahan EJ 1981 Acrodermatitis enteropathica and the immunological role of zinc. In: Sasai B, Good RA (eds) Immunodermatology. Plenum Medical Book Company, New York, pp 437-447

22. Allen JI, Kay NE, McLain CJ 1981 Severe zinc deficiency in humans: association with a reversible $T$ lymphocyte dysfunction. Ann Intern Med 95:154157

23. Bjorksten B, Back O, Gustavson KH, Hallmans G, Hagglof B, Taruvik A 1980 Zinc and immune function in Down's syndrome. Acta Paediatr Scand 69:183-187

24. Milunsky A, Hackley BM, Halsted JA 1970 Plasma, erythrocyte and leucocyte zinc levels in Down's syndrome. J Ment Defic Res 14:99-105

25. Fabris N, Amadio L, Lacastro F, Mocchegiani E, Zanotti M, Franceschi C 1984 Thymic hormone deficiency in normal ageing and Down's syndrome: is there a primary failure of the thymus? Lancet 1:983-986

26. Neve J, Molle L, Hanocq M, Sinet PM, Van Geffel R 1983 Erythrocyte and plasma trace element levels in clinical assessments. Biol Trace Element Res
5:75-79

27. Bach JF, Dardenne M 1984 Clinical aspects of thymulin (FTS). In: Goldstein AL (ed) Thymic Hormones and Lymphokines. Plenum Press, New York, pp 593-560

28. Boyum A 1976 Isolation of lymphocytes, granulocytes and macrophages Scand J Immunol 5 (suppl 5):9-15

29. Singh VK, Jakubovic A, Thomas DA 1980 Suppressive effects of methadone on human blood lymphocytes. Immunol Lett $2: 177-180$

30. SAS PC. SAS Institute Inc, Cary, NC 